\title{
Optical Properties of ZnO-Alloyed Nanocrystalline Films
}

\author{
Hui Che, ${ }^{1}$ Jesse Huso, ${ }^{1}$ John L. Morrison, ${ }^{1}$ Dinesh Thapa, ${ }^{1}$ Michelle Huso, ${ }^{1}$ \\ Wei Jiang Yeh,, ${ }^{1}$ M. C. Tarun, ${ }^{2}$ M. D. McCluskey, ${ }^{2}$ and Leah Bergman' \\ ${ }^{1}$ Department of Physics, University of Idaho, Moscow, ID 83844-0903, USA \\ ${ }^{2}$ Department of Physics and Materials Science, Washington State University, Pullman, WA 99164-2814, USA
}

Correspondence should be addressed to Leah Bergman, lbergman@uidaho.edu

Received 27 November 2011; Revised 28 February 2012; Accepted 8 March 2012

Academic Editor: J. C. Sczancoski

Copyright () 2012 Hui Che et al. This is an open access article distributed under the Creative Commons Attribution License, which permits unrestricted use, distribution, and reproduction in any medium, provided the original work is properly cited.

\begin{abstract}
$\mathrm{ZnO}$ is emerging as one of the materials of choice for UV applications. It has a deep excitonic energy level and a direct bandgap of $\sim 3.4 \mathrm{eV}$. Alloying $\mathrm{ZnO}$ with certain atomic constituents adds new optical and electronic functionalities to $\mathrm{ZnO}$. This paper presents research on $\mathrm{Mg}_{x} \mathrm{Zn}_{1-x} \mathrm{O}$ and $\mathrm{ZnS}_{1-x} \mathrm{O}_{x}$ nanocrystalline flexible films, which enable tunable optical properties in the deep$\mathrm{UV}$ and in the visible range. The $\mathrm{ZnO}$ and $\mathrm{Mg}_{0.3} \mathrm{Zn}_{0.7} \mathrm{O}$ films were found to have bandgaps at 3.35 and $4.02 \mathrm{eV}$, respectively. The photoluminescence of the $\mathrm{Mg}_{0.3} \mathrm{Zn}_{0.7} \mathrm{O}$ exhibited a bandedge emission at $3.95 \mathrm{eV}$, and at lower energy $3.38 \mathrm{eV}$ due to the limited solubility inherent to these alloys. $\mathrm{ZnS}_{0.76} \mathrm{O}_{0.24}$ and $\mathrm{ZnS}_{0.16} \mathrm{O}_{0.84}$ were found to have bandgaps at 3.21 and $2.65 \mathrm{eV}$, respectively. The effect of nitrogen doping on $\mathrm{ZnS}_{0.16} \mathrm{O}_{0.84}$ is discussed in terms of the highly lattice mismatched nature of these alloys and the resulting valence-band modification.
\end{abstract}

\section{Introduction: The $\operatorname{Mg}_{x} \mathrm{Zn}_{1-x} \mathrm{O}$ and $\mathrm{ZnS}_{1-x} \mathbf{O}_{x}$ Alloy Systems}

Zinc oxide $(\mathrm{ZnO})$ is a direct bandgap semiconductor with a bandgap of $\sim 3.37 \mathrm{eV}$ at room temperature and relatively deep excitonic binding energy of $60 \mathrm{meV}$, both attributes of which make $\mathrm{ZnO}$ an efficient UV optical material at and above room temperature [1-6]. Due to their environmentally friendly chemical nature, resistivity to harsh environments, and deep excitonic level, $\mathrm{ZnO}$ as well as $\mathrm{Mg}_{x} \mathrm{Zn}_{1-x} \mathrm{O}$ (where $x$ is the composition) are emerging materials capable of highefficiency luminescence in a wide range of the ultraviolet (UV) spectrum [6-8].

$\mathrm{ZnO}$ has the hexagonal wurtzite structure, while $\mathrm{MgO}$ has the $\mathrm{NaCl}$ cubic structure with a direct bandgap $\sim 7.5 \mathrm{eV}$ and excitonic binding energy $\sim 140 \mathrm{meV}[9,10]$. Alloying these two provides a family of materials with tunable optical and electronic properties. Although the atomic sizes of $\mathrm{Mg}$ and $\mathrm{Zn}$ are comparable, that is, $\mathrm{Mg}_{x} \mathrm{Zn}_{1-x} \mathrm{O}$ is considered to be a lattice-matched system, due to the two different crystal structures the two oxides do not show complete solid solubility. Despite this inherent property, $\mathrm{Mg}_{x} \mathrm{Zn}_{1-x} \mathrm{O}$ alloys with tunable optical properties over a large composition range have been realized $[7,8,11,12]$. The exact properties were found to be somewhat growth dependant; the general trend of the bandgap behavior indicates that at $\mathrm{Mg}$ composition up to $\sim 35 \%$ the alloy is soluble and has mainly the wurtzite structure with bandgap spanning the range of $\sim 3.4-4 \mathrm{eV}$. At the composition range of $\sim 35 \%-60 \%$ (referred to as the transition range), the alloy is phase separated into the wurtzite and the cubic structures, and at $\mathrm{Mg}$ composition above $\sim 60 \%$ it has the cubic structure and bandgaps tuned in the range $\sim 5-7 \mathrm{eV}$. Figure 1 presents a general schematic of the bandgap behavior of the $\mathrm{Mg}_{x} \mathrm{Zn}_{1-x} \mathrm{O}$ alloy system.

Another alloy system that may be proven to be very useful is $\mathrm{ZnS}_{1-x} \mathrm{O}_{x}$ that potentially should allow tuneability into the visible range. To date, very little is known about its material, electronic and optical properties [13]. ZnS with the zinceblende structure has a direct bandgap $\sim 3.84 \mathrm{eV}$ [14]. The substituting anions in the $\mathrm{ZnS}_{1-x} \mathrm{O}_{x}$ alloy have large differences in size and chemical properties: the covalent radii of sulfur and oxygen are $1.02 \AA$ and $0.73 \AA$, respectively, and their electronegative values are 2.58 and 3.44 . This alloy is considered to be a highly lattice mismatched system. As a consequence, the $\mathrm{ZnS}_{1-x} \mathrm{O}_{x}$ alloy system has been predicted to have unusual material properties that should add new 


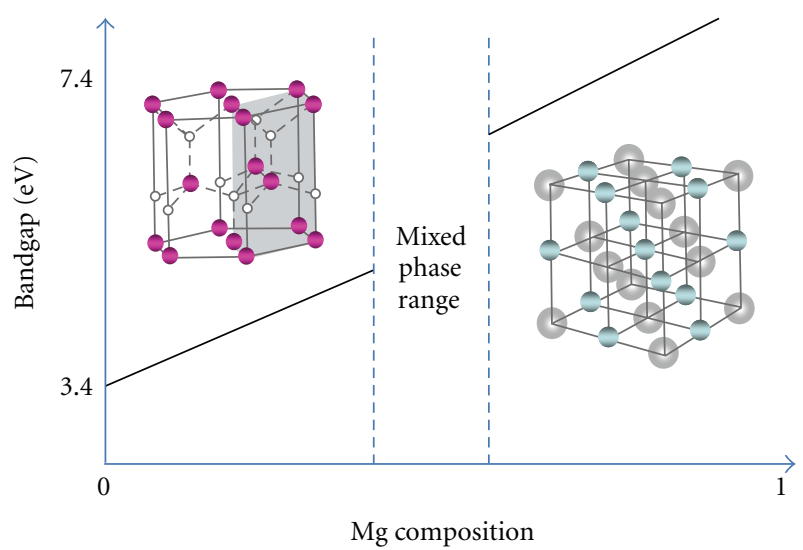

Figure 1: Diagram describing the behavior of the bandgap of $\mathrm{Mg}_{x} \mathrm{Zn}_{1-x} \mathrm{O}$ as a function of $\mathrm{Mg}$ composition.

functionality to $\mathrm{ZnO}[14,15]$. First-principle plane-wave calculations by Moon et al. on highly mismatched II-VI alloys have predicted that these alloys possess huge bowing coefficients, that is, a significant deviation from linearity upon going from one end member of the alloy to the second [14]. Figure 2 presents the calculated bandgap of $\mathrm{ZnS}_{1-x} \mathrm{O}_{x}$ as a function of composition $x$ [14]. In general terms, the cause of the large bowing parameter of these highly mismatched alloys has been attributed to hybridization and creation of resonance defect-like states at the gap edges. For example, at the low regime of sulfur concentration, the bowing into the visible is due to the raising of the valence band, while the conduction band is only slightly affected by the alloying [15]. Several groups reported similar unusual alloy properties of other highly mismatched systems such as $\mathrm{GaAs}_{x} \mathrm{~N}_{1-x}$ and $\mathrm{GaN}_{1-x} \mathrm{Bi}_{x}$ [16-18]. In Figure 2, the square dots represent our experimental result that will be discussed in detail in the following sections. The advantages of having a highly lattice mismatched alloy is that for a relative small concentration of sulfur a significant modification of the bandgap can be attained that enables optical properties in the visible.

\section{Experiment}

The substrate used for the experiments is commercially available fluorinated ethylene propylene (FEP), also known as Teflon FEP, which is flexible and UV-transparent. The $\mathrm{ZnO}$ and the $\mathrm{Mg}_{0.3} \mathrm{Zn}_{0.7} \mathrm{O}$ samples were grown at room temperature on prepared FEP substrates utilizing magnetron sputtering of $\mathrm{Zn}$ and $\mathrm{Mg}-\mathrm{Zn}$ targets, respectively, under argon plasma. The samples were then oxidized for 2 hours under an atmosphere of $99.99 \%$ pure oxygen at a temperature of $275^{\circ} \mathrm{C}$. The $\mathrm{ZnS}_{x} \mathrm{O}_{1-x}$ films were grown by a reactive $\mathrm{RF}$ magnetron sputtering system, at $300^{\circ} \mathrm{C}$, using a ceramic $\mathrm{ZnS}$ target and argon as the sputtering gas. In addition to the argon, controlled amounts of oxygen and nitrogen were introduced during the growth process so to achieve nitrogendoped $\mathrm{ZnS}_{x} \mathrm{O}_{1-x}$ films. The nitrogen pressure in the chamber was approximately $2.1 \times 10^{-5}$ Torr. The films were sputtered

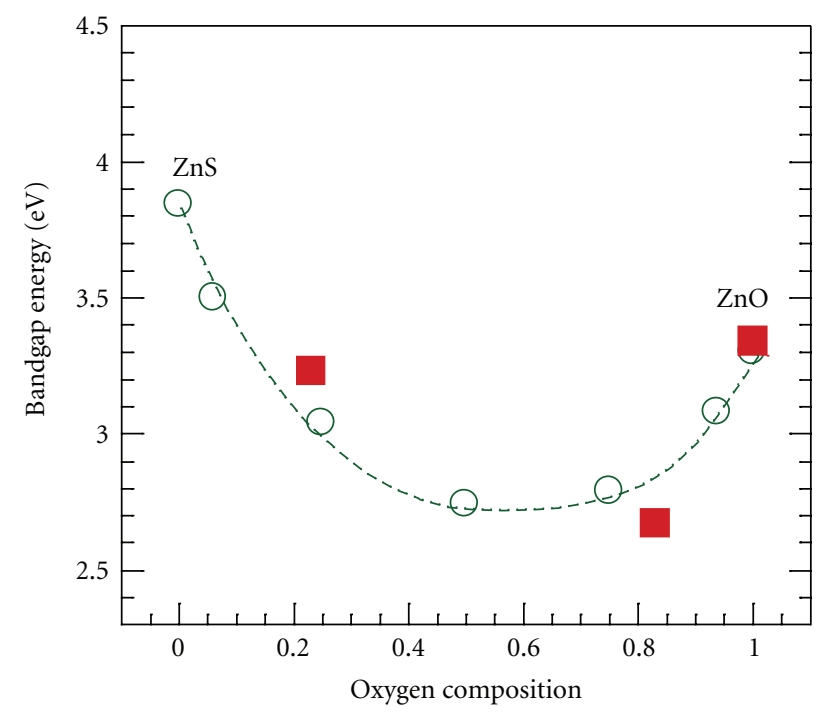

FIGURE 2: The bandgap energy of $\mathrm{ZnS}_{1-x} \mathrm{O}_{x}$ as a function of oxygen concentration. The theoretical prediction (circles) is from [14], and experimental results (squares) are from the research in this paper.

at $50 \mathrm{~W}$ for 1.5 hours. The nitrogen incorporation was verified by X-ray photoelectron spectroscopy (XPS). The compositions of the alloys were determined via energy dispersive spectroscopy (EDS).

The photoluminescence (PL) experiments utilized a JY-Horiba micro-Raman/PL system consisting of a highresolution T-64000 triple monochromator and a UV confocal microscope capable of focusing to a spot size of $1 \mu \mathrm{m}$ diameter. A CW-Kimmon laser with a wavelength of $325 \mathrm{~nm}(3.8 \mathrm{eV})$ and a Lexel Laser at $244 \mathrm{~nm}(5.1 \mathrm{eV})$ were used as the excitation source for the PL, and the cold temperature PL measurements were conducted in an INSTEC UV-compatible microcell. The subgap PL spectra were obtained, at room temperature, using a JY-Horiba FluoroLog-3 spectrofluorometer with a $450-\mathrm{W}$ xenon lamp as the excitation source at $490 \mathrm{~nm}$. The transmission spectra were acquired at room temperature using an Agilent Cary300 system. The transmission data were acquired with a double-beam technique, and the data were normalized relative to the transparent region. Both procedures allow us to neglect equipment response as well as Fresnel reflections and scattering losses at the long wave length limit up to near the bandgap value.

\section{Results and Discussion}

Figures 3 and 4 present scanning electron microscope (SEM) images and photographs of the $\mathrm{ZnO}$ and $\mathrm{Mg}_{0.3} \mathrm{Zn}_{0.7} \mathrm{O}$ flexible films [6], and Figure 5 presents those of the $\mathrm{ZnS}_{0.16} \mathrm{O}_{0.84}$. As is depicted in the figures, the morphology of the films is structured: in the nanoscale regime for $\mathrm{ZnO}$ and $\mathrm{Mg}_{0.3} \mathrm{Zn}_{0.7} \mathrm{O}$ and at submicron regime for $\mathrm{ZnS}_{0.16} \mathrm{O}_{0.84}$. An extended discussion on the material properties of our flexible films can be found in [6]. In order to estimate the bandgaps of the alloys, transmission spectra were acquired at room 


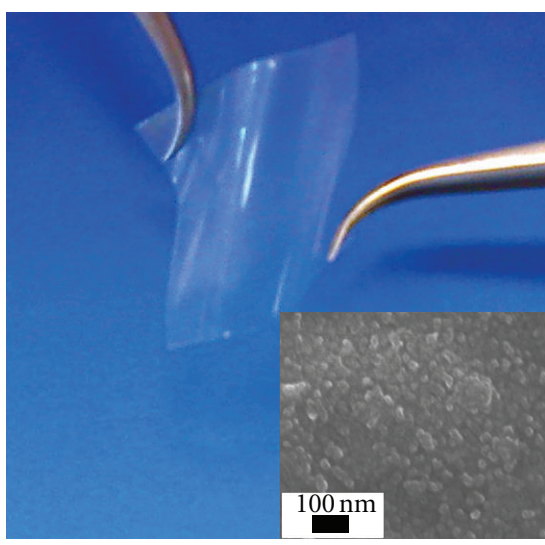

Figure 3: A photograph and an SEM image (inset) of the $\mathrm{ZnO}$ nanocrystalline film.
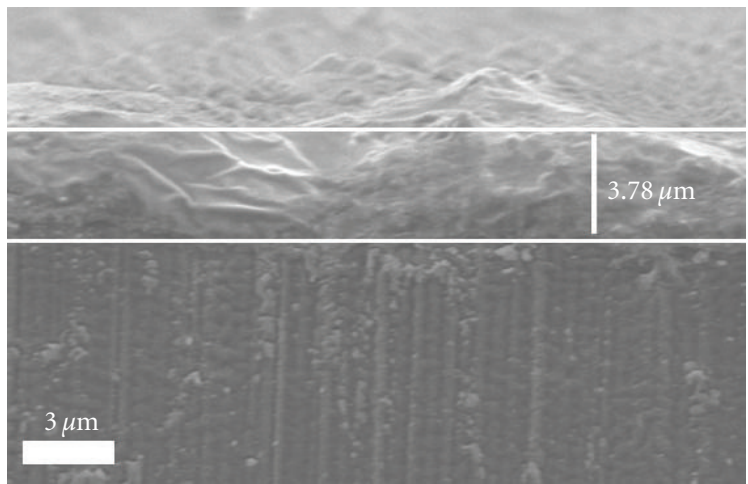

FIgure 4: A cross section SEM image of the $\mathrm{Mg}_{0.3} \mathrm{Zn}_{0.7} \mathrm{O}$ films.

temperature and are presented in Figures 6(a) and 6(b). As can be seen in the figure, the alloys exhibit a rather broad absorption edge that is attributed to localized states due to the inherent alloy disorder and phase segregations. When the absorbance bandgap is not sharply defined, the usual method of extrapolation [20] may not render good results. To estimate the bandgap in such cases, transmission derivative procedures can be utilized, which were successfully used previously for the analysis of the bandgaps of $\mathrm{Mg}_{x} \mathrm{Zn}_{1-x} \mathrm{O}$ and $\operatorname{In}_{x} \mathrm{Ga}_{1-x} \mathrm{~N}[6,21-23]$. In the following, we present the derivation of the method applicable to direct bandgap transitions.

The transmission through a film may be approximated as $[20,24]$

$$
T(E) \approx[1-R(E)]^{2} e^{-\alpha(E) t},
$$

where $E$ is the energy of the incident light, $R$ is the reflectance, and $t$ is the thickness of the film. In (1), the absorption coefficient $\alpha$ may be written as [25]

$$
\alpha(E)=\frac{C}{E \eta_{r}(E)} \sqrt{E-E_{g}},
$$

where $\eta_{r}(E)$ is the energy-dependent index of refraction and $C$ is a constant. In obtaining the transmission derivative

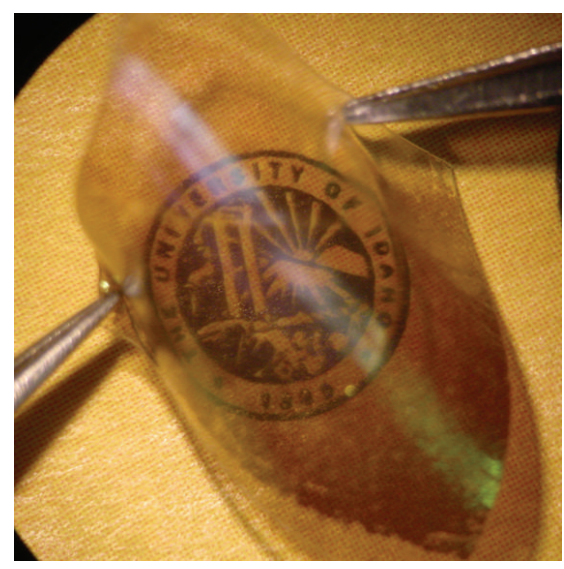

(a)

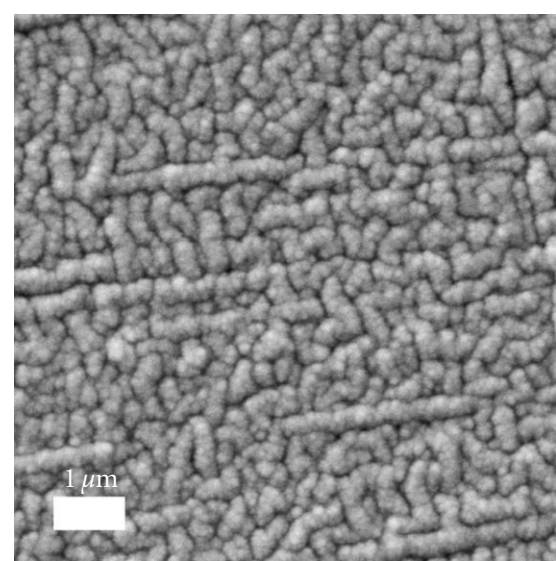

(b)

Figure 5: A photograph (a) and an SEM image (b) of the $\mathrm{ZnS}_{0.16} \mathrm{O}_{0.84}$ nanocrystalline film.

one needs to consider the behavior of the reflectance near the bandgap energy. It can be shown that as $E \rightarrow E_{g}$, the quantities $1-R(E)$ and $d R(E) / d E$ remain finite at energies in the vicinity of $E_{g}$ due to the existence of a band tail which prevents a singularity-type behavior. Experimental results concerning $\mathrm{ZnO}$ thin film properties indeed found that the reflectance and its derivative are well-behaved quantities near the bandgap energy [26]. Consequently, for the purposes of our analysis we may write the transmission through a direct gap semiconductor as

$$
T(E)=e^{-C^{*}\left(1 / E \eta_{r}(E)\right) \sqrt{E-E_{g}},}
$$

where $C^{*}=C t$. The first derivative of $T(E)$ with respect to energy is then

$$
\begin{aligned}
\frac{d T}{d E}=-C^{*}\left[-\frac{1}{E^{2} \eta_{r}(E)} \sqrt{E-E_{g}}\right. \\
\left.\quad-\frac{d \eta_{r}(E)}{d E} \frac{\sqrt{E-E_{g}}}{E\left(\eta_{r}(E)\right)^{2}}+\frac{1}{2 E \eta_{r}(E) \sqrt{E-E_{g}}}\right] \\
\cdot \exp \left[-C^{*} \frac{1}{E \eta_{r}(E)} \sqrt{E-E_{g}}\right],
\end{aligned}
$$




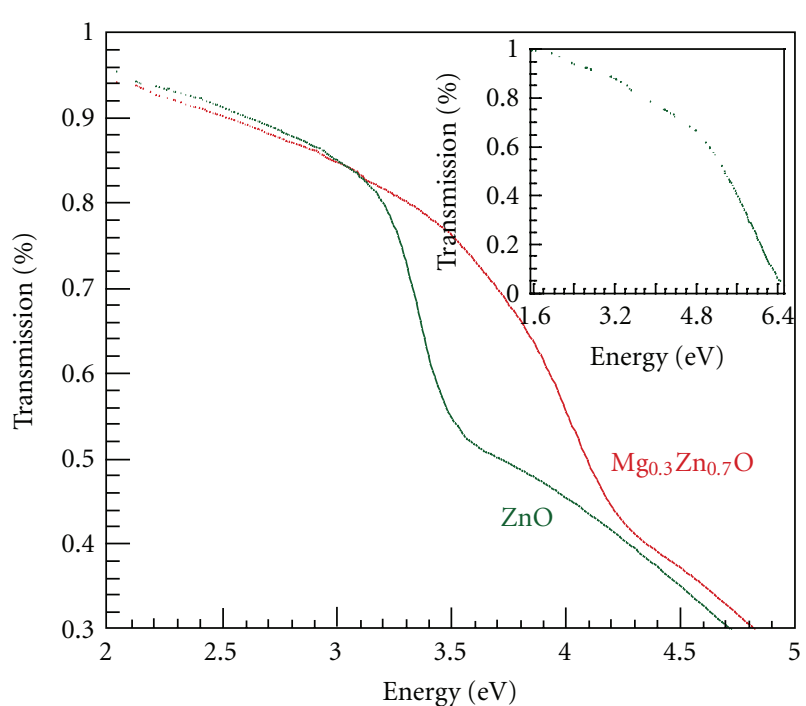

(a)

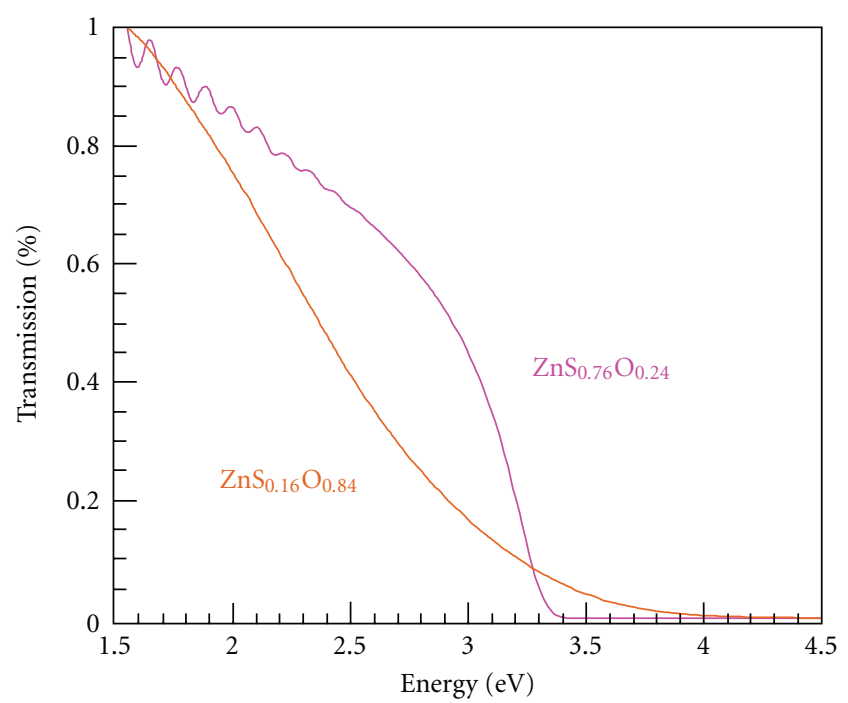

(b)

Figure 6: The transmission spectra of the $\mathrm{ZnO}$ and $\mathrm{Mg}_{0.3} \mathrm{Zn}_{0.7} \mathrm{O}$ films (a) and those of the $\mathrm{ZnS}_{0.76} \mathrm{O}_{0.24}$ and $\mathrm{ZnS}_{0.16} \mathrm{O}_{0.84}$ (b). The inset in (a) is the transmission spectrum of the FEP substrate.

and at the limit $E \rightarrow E_{g}$, one gets

$$
\lim _{E \rightarrow E_{g}} \frac{d T}{d E}=-1 C^{*}\left(-0-0+\frac{1}{0}\right) \longrightarrow-\infty,
$$

which yields a spike towards negative infinity at $E=E_{g}$. It was assumed that $d \eta_{r}(E) / d E$ is continuous around $E_{g}$ due to band tail states as was discussed in $[27,28]$. Thus, a plot of $d T / d E$ versus $E$ will exhibit a strong singularity at the bandgap energy. In realistic cases, absorption tails exist, which soften the divergence and result in well-defined peaks around the gap energy, as also can be seen in Figure 7.

From Figure 7, the $\mathrm{ZnO}$ film has a bandgap of $\sim 3.35 \mathrm{eV}$ at room temperature, which is consistent with previous reports [29], while that of $\mathrm{Mg}_{0.3} \mathrm{Zn}_{0.7} \mathrm{O}$ is at $\sim 4.02 \mathrm{eV}$, a value similar to that previously observed for thin films grown

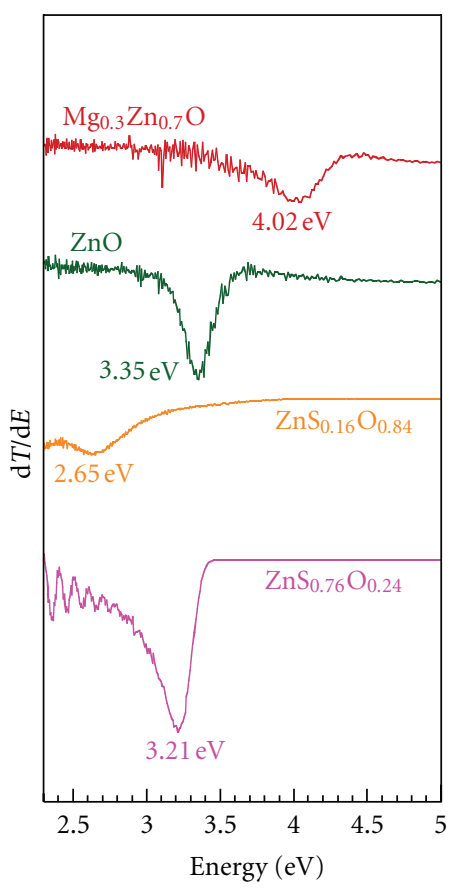

FIgURE 7: The plots of the derivative of the transmission with respect to energy.

via the pulsed laser deposition [7]. The bandgap of the $\mathrm{ZnS}_{0.16} \mathrm{O}_{0.84}$ and $\mathrm{ZnS}_{0.76} \mathrm{O}_{0.24}$ alloys are 2.65 and $3.21 \mathrm{eV}$, respectively, values which agree with those predicated from the first-principle plane-wave calculations presented in Figure 2 [14]. As such the transmission derivative method estimates well the bandgap of our materials.

The PL properties of the films presented in Figures 8 and 9 show that the $\mathrm{Mg}_{0.3} \mathrm{Zn}_{0.7} \mathrm{O}$ film has two optical emissions: one at 3.38 and the other at a $3.95 \mathrm{eV}$. At $\mathrm{Mg}$ composition of $\sim 30 \%$, the sample is expected to be phase segregate due to the limited solubility of the $\mathrm{MgO}-\mathrm{ZnO}$ solid solution (see Figure 1). Accordingly, the peak emissions at 3.38 and at $3.95 \mathrm{eV}$ are attributed to $\mathrm{ZnO}$-rich and to $\mathrm{MgO}$-rich domains, respectively. The $\mathrm{ZnS}_{0.16} \mathrm{O}_{0.84}$ film was found to luminesce at the visible range of $2.48 \mathrm{eV}$; however, the PL intensity was only visible at $77 \mathrm{~K}$, and the PL of the $\mathrm{ZnS}_{0.76} \mathrm{O}_{0.24}$ was found to be extremely weak. The low efficiency of the PL may be a result of a significant concentration of structural defects due to the highly mismatched nature of this alloy system. As can be seen in Figure 5(b), the morphology of the sample is very coarse, unlike that of the $\mathrm{MgZnO}$ film presented in Figure 3. These structural defects may act as nonradiative centers impeding the PL efficiency.

Mapping of the bandgap via luminescence is a very informative technique for the study of deep impurities and defect centers in $\mathrm{ZnO}$. $\mathrm{ZnO}$ has been found to have a characteristic broad In-gap PL with components in the green, yellow, and red part of the spectrum [30-32]. Although the origins of these PL are as yet under investigation, the consensus is that they are related to oxygen and zinc vacancies as well as to interstitial oxygen. In addition to those intrinsic centers, 


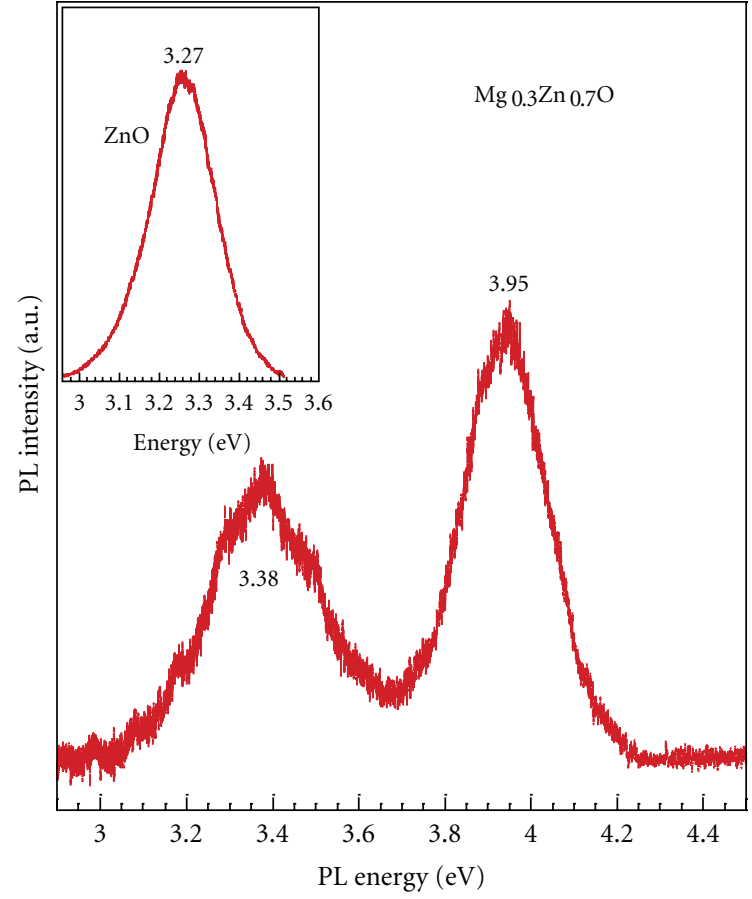

Figure 8: The room temperature PL spectrum of the $\mathrm{Mg}_{0.3} \mathrm{Zn}_{0.7} \mathrm{O}$ sample. The inset is the spectrum of the $\mathrm{ZnO}$ sample.

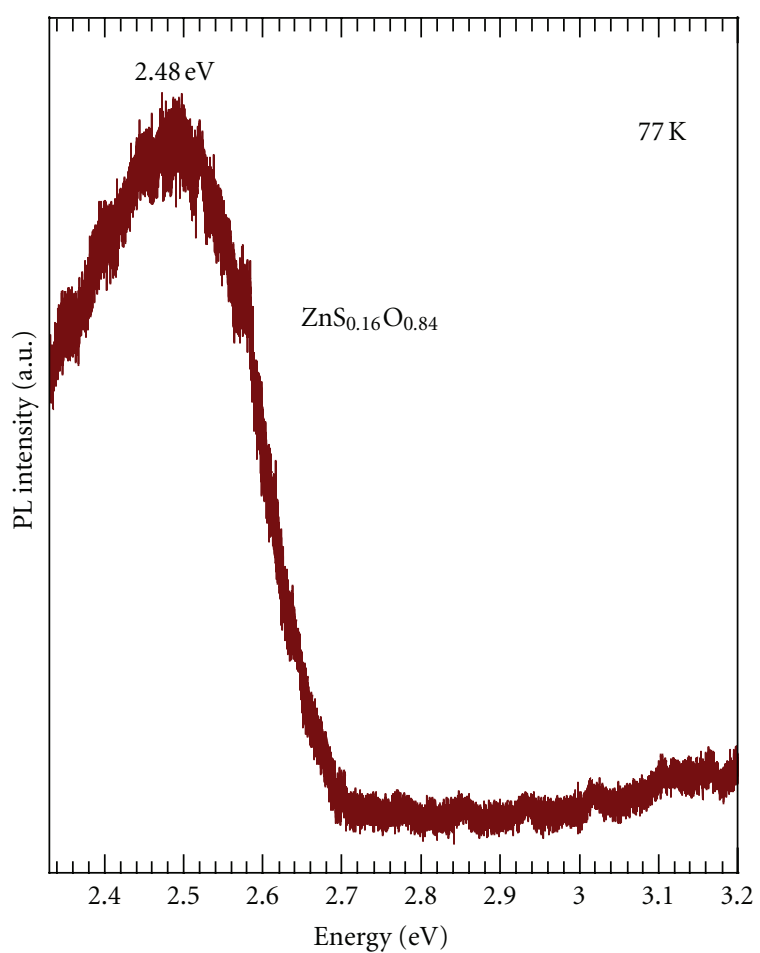

Figure 9: The PL spectrum of the $\mathrm{ZnS}_{0.16} \mathrm{O}_{0.84}$ sample. The PL was acquired at $77 \mathrm{~K}$.

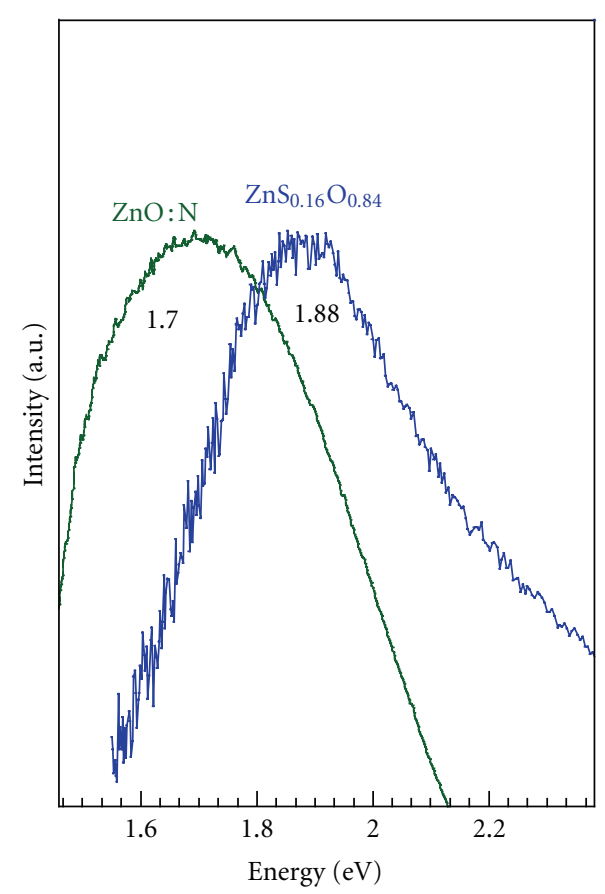

Figure 10: The In-gap PL of a nitrogen-doped $\mathrm{ZnO}$ (from [19]) and that of nitrogen-doped $\mathrm{ZnS}_{0.16} \mathrm{O}_{0.84}$ film.

it was established that nitrogen doped $\mathrm{ZnO}$ also exhibits a broad in-gap PL at $\sim 1.7 \mathrm{eV}[19,33]$. Recent findings concerning the characteristics of nitrogen in $\mathrm{ZnO}$ found that nitrogen is a deep acceptor with acceptor level $1.3 \mathrm{eV}$ above the valence band maximum $[19,34]$.

Unlike the deep level of nitrogen in $\mathrm{ZnO}$, in $\mathrm{ZnS}_{1-x} \mathrm{O}_{x}$ the acceptor level was predicated to be relatively shallow for the low regime of sulfur concentration [15]. As was discussed in the introduction, this comes about due to the rising of the valence band toward the acceptor level upon alloying. The implication of the phenomenon is that $p$-type doping might be realized in lightly alloyed $\mathrm{ZnO}$. Figure 10 presents the in-gap PL spectrum of nitrogen-doped $\mathrm{ZnO}$ taken from [19] and that of the $\mathrm{ZnS}_{0.16} \mathrm{O}_{0.84}$ film that exhibits a broad PL band at $\sim 1.88 \mathrm{eV}$. The close proximity of the two peak positions and their similar linewidths suggest that that PL of the $\mathrm{ZnS}_{0.16} \mathrm{O}_{0.84}$ is due to nitrogen centers. Based on the ingap PL emission, and the bandgap found for the $\mathrm{ZnS}_{0.16} \mathrm{O}_{0.84}$, a tentative bandgap diagram is presented in Figure 11 for which the nitrogen impurity has a level of $\sim 0.37 \mathrm{eV}$ above the valence band. In this diagram, it was assumed that the lattice coupling of the nitrogen center in $\mathrm{ZnS}_{0.16} \mathrm{O}_{0.84}$ is similar to that calculated for the same center in $\mathrm{ZnO}$, that is, $\sim 0.4 \mathrm{eV}$; for a smaller coupling, the nitrogen level should be a little higher and is at $\sim 0.77 \mathrm{eV}$ above the valence band in the limiting case of no coupling. For intermediate coupling energy $\sim 0.22 \mathrm{eV}$, the nitrogen level will be at $0.55 \mathrm{eV}$, which is aligned with that of $\mathrm{ZnO}$. Several factors may impact the observed in-gap PL energies, such as residual stress and structural defect-states, that might cause some discrepancy between the theory and experiments. Study of 


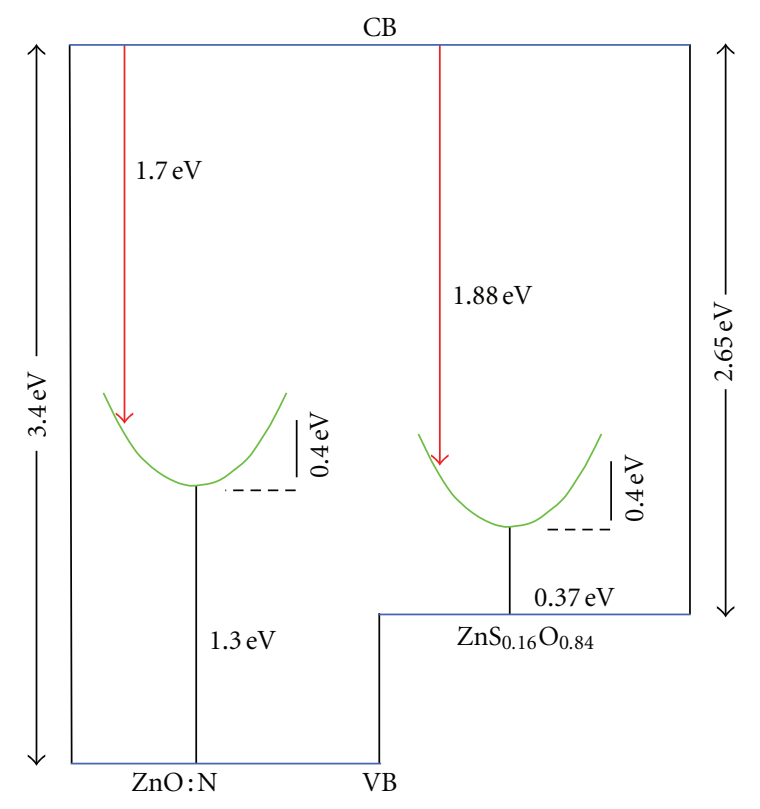

Figure 11: A schematic of bandgap diagram of the samples described in Figure 10.

nitrogen-doped $\mathrm{ZnS}$ films demonstrated that effective $p$ type conductivity can be readily attained, and a shallow nitrogen acceptor level about $0.19 \mathrm{eV}$ above the valance band was suggested [35]. Thus, $\mathrm{ZnS}_{1-x} \mathrm{O}_{x}$ may have potential as a material component in $\mathrm{ZnO}$-based devices when $p$-type doping is required.

\section{Conclusions}

$\mathrm{ZnS}_{0.16} \mathrm{O}_{0.84}, \mathrm{ZnS}_{0.76} \mathrm{O}_{0.24}, \mathrm{ZnO}$, and $\mathrm{Mg}_{0.3} \mathrm{Zn}_{0.7} \mathrm{O}$ nanocrystalline films were grown via a sputtering technique on a flexible substrate with the objective of achieving $\mathrm{ZnO}$-based alloys with bandgaps spanning the visible to the UV. The bandgaps of the films were found to be $2.65,3.21,3.35$, and $4.02 \mathrm{eV}$, respectively. The PL spectra of the $\mathrm{Mg}_{0.3} \mathrm{Zn}_{0.7} \mathrm{O}$ exhibit a band-edge peak at $3.95 \mathrm{eV}$, and one at $3.38 \mathrm{eV}$ that is attributed to a $\mathrm{Zn}$-rich $\mathrm{MgZnO}$ segregates that arise from the inherent low solubility limit of this alloy system. The PL intensity of the $\mathrm{ZnS}_{0.16} \mathrm{O}_{0.84}$ and $\mathrm{ZnS}_{0.76} \mathrm{O}_{0.24}$ films was found to be extremely week. Structural defects, arising from the highly mismatched alloy constituents, were discussed to be the nonradiative optical centers. Future study will investigate whether the $\mathrm{ZnS}_{1-x} \mathrm{O}_{x}$ alloy system possesses an efficient PL. The $\mathrm{ZnS}_{0.16} \mathrm{O}_{0.84}$ was found to have an in-gap PL attributed to nitrogen centers, and a nitrogen energy level at the range $\sim 0.37-0.77 \mathrm{eV}$ relative to the valence-band was proposed.

\section{Acknowledgment}

This research was supported by the US Department of Energy, Office of Basic Energy Science, Division of Materials Science and Engineering under Award DE-FG0207ER46386.

\section{References}

[1] Y. S. Park, C. W. Litton, T. C. Collins, and D. C. Reynolds, "Exciton spectrum of ZnO," Physical Review, vol. 143, no. 2, pp. 512-519, 1966.

[2] W. Y. Liang and A. D. Yoffe, "Transmission spectra of $\mathrm{ZnO}$ single crystals," Physical Review Letters, vol. 20, no. 2, pp. 5962, 1968.

[3] R. Laskowski and N. E. Christensen, "Ab initio calculation of excitons in ZnO," Physical Review B, vol. 73, no. 4, Article ID 045201, 7 pages, 2006.

[4] B. K. Meyer, H. Alves, D. M. Hofmann et al., "Bound exciton and donor-acceptor pair recombinations in ZnO," Physica Status Solidi, vol. 241, no. 2, pp. 231-260, 2004.

[5] X.-B. Chen, J. Huso, J. L. Morrison, and L. Bergman, "The properties of $\mathrm{ZnO}$ photoluminescence at and above room temperature," Journal of Applied Physics, vol. 102, no. 11, Article ID 116105, 2007.

[6] J. Huso, J. L. Morrison, H. Che et al., "ZnO and MgZnO nanocrystalline flexible films: optical and material properties," Journal of Nanomaterials, vol. 2011, Article ID 691582, 7 pages, 2011.

[7] A. Ohtomo, M. Kawasaki, T. Koida et al., " $\mathrm{Mg}_{\mathrm{x}} \mathrm{Zn}_{1-\mathrm{x}} \mathrm{O}$ as a IIVI widegap semiconductor alloy," Applied Physics Letters, vol. 72, no. 19, pp. 2466-2468, 1998.

[8] S. Choopun, R. D. Vispute, W. Yang, R. P. Sharma, T. Venkatesan, and H. Shen, "Realization of band gap above $5.0 \mathrm{eV}$ in metastable cubic-phase $\mathrm{Mg}_{\mathrm{x}} \mathrm{Zn}_{1-\mathrm{x}} \mathrm{O}$ alloy films," Applied Physics Letters, vol. 80, no. 9, pp. 1529-1531, 2002.

[9] R. C. Whited, C. J. Flaten, and W. C. Walker, "Exciton thermoreflectance of $\mathrm{MgO}$ and CaO," Solid State Communications, vol. 13, no. 11, pp. 1903-1905, 1973.

[10] P. D. Johnson, "Some optical properties of MgO in the vacuum ultraviolet," Physical Review, vol. 94, no. 4, pp. 845-846, 1954.

[11] U. Sahaym, M. G. Norton, J. Huso, J. L. Morrison, H. Che, and L Bergman, "Microstructure evolution and photoluminescence in nanocrystalline $\mathrm{Mg}_{\mathrm{x}} \mathrm{Zn}_{1-\mathrm{x}} \mathrm{O}$ thin films," Nanotechnology, vol. 22, no. 42, Article ID 425706, 2011.

[12] X. Du, Z. Mei, Z. Liu et al., "Controlled growth of high-quality $\mathrm{ZnO}$-based films and fabrication of visible-blind and solarblind ultra-violet detectors," Advanced Materials, vol. 21, no. 45, pp. 4625-4630, 2009.

[13] B. K. Meyer, A. Polity, B. Farangis et al., "Structural properties and bandgap bowing of $\mathrm{ZnO}_{1-\mathrm{x}} \mathrm{S}_{\mathrm{x}}$ thin films deposited by reactive sputtering," Applied Physics Letters, vol. 85, no. 21, pp. 4929-4931, 2004.

[14] C.-Y. Moon, S.-H. Wei, Y. Z. Zhu, and G. D. Chen, "Band-gap bowing coefficients in large size-mismatched II-VI alloys: firstprinciples calculations," Physical Review B, vol. 74, Article ID 233202, 4 pages, 2006.

[15] C. Persson, C. Platzer-Björkman, J. Malmström, T. Törndahl, and M. Edoff, "Strong valence-band offset bowing of $\mathrm{ZnO}_{1-\mathrm{x}} \mathrm{S}_{\mathrm{x}}$ enhances p-type nitrogen doping of $\mathrm{ZnO}$-like alloys," Physical Review Letters, vol. 97, no. 14, Article ID 146403, 2006.

[16] J. Wu, W. Walukiewicz, and E. E. Haller, "Band structure of highly mismatched semiconductor alloys: coherent potential approximation," Physical Review B, vol. 65, no. 23, Article ID 233210, 4 pages, 2002.

[17] K. M. Yu, W. Walukiewicz, W. Shan et al., "Synthesis and optical properties of II-O-VI highly mismatched alloys," Journal of Applied Physics, vol. 95, no. 11 I, pp. 6232-6238, 2004. 
[18] A. X. Levander, K. M. Yu, S. V. Novikov et al., "Gan1-xbix: extremely mismatched semiconductor alloys," Applied Physics Letters, vol. 97, no. 14, Article ID 141919, 2010.

[19] M. C. Tarun, M. Z. Iqbal, and M. D. McCluskey, "Nitrogen is a deep acceptor in ZnO," AIP Advances, vol. 1, no. 2, Article ID 022105, 7 pages, 2011.

[20] J. I. Pankove, Optical Processes in Semiconductors, Dover, New York, NY, USA, 1971.

[21] M. Wang, E. J. Kim, S. Kim et al., "Optical and structural properties of sol-gel prepared MgZnO alloy thin films," Thin Solid Films, vol. 516, no. 6, pp. 1124-1129, 2008.

[22] R. Viswanatha, S. Chakraborty, S. Basu, and D. D. Sarma, "Blue-emitting copper-doped zinc oxide nanocrystals," Journal of Physical Chemistry B, vol. 110, no. 45, pp. 22310-22312, 2006.

[23] C. A. Parker, J. C. Roberts, S. M. Bedair et al., "Optical band gap dependence on composition and thickness of $\operatorname{In}_{\mathrm{x}} \mathrm{Ga}_{1-\mathrm{x}} \mathrm{N}$ $(0<\mathrm{x}<0.25)$ grown on gan," Applied Physics Letters, vol. 75, no. 17 , pp. 2566-2568, 1999.

[24] B. Ullrich, C. Zhang, E. F. Schubert, J. E. Cunningham, and K. V. Klitzing, "Transmission spectroscopy on sawtooth-doping superlattices," Physical Review B, vol. 39, no. 6, pp. 3776-3779, 1989.

[25] B. K. Ridley, Quantum Processes in Semiconductors, Clarendon Press, Oxford University Press, New York, NY, USA, 1999.

[26] R. E. Marotti, D. N. Guerra, C. Bello, G. Machado, and E. A. Dalchiele, "Bandgap energy tuning of electrochemically grown $\mathrm{ZnO}$ thin films by thickness and electrodeposition potential," Solar Energy Materials and Solar Cells, vol. 82, no. 1-2, pp. 85103, 2004.

[27] F. Stern, "Dispersion of the index of refraction near the absorption edge of semiconductors," Physical Review, vol. 133, no. 6A, pp. A1653-A1664, 1964.

[28] C. Tanguy, "Refractive index of direct bandgap semiconductors near the absorption threshold: influence of excitonic effects," IEEE Journal of Quantum Electronics, vol. 32, no. 10, pp. 1746-1751, 1996.

[29] V. Srikant and D. R. Clarke, "On the optical band gap of zinc oxide," Journal of Applied Physics, vol. 83, no. 10, pp. 54475451, 1998.

[30] D. Li, Y. H. Leung, A. B. Djurišić et al., "Different origins of visible luminescence in $\mathrm{ZnO}$ nanostructures fabricated by the chemical and evaporation methods," Applied Physics Letters, vol. 85, no. 9, pp. 1601-1603, 2004.

[31] Y. W. Heo, D. P. Norton, and S. J. Pearton, “Origin of green luminescence in $\mathrm{ZnO}$ thin film grown by molecular-beam epitaxy," Journal of Applied Physics, vol. 98, no. 7, Article ID 073502, 6 pages, 2005.

[32] A. B. Djurišić, Y. H. Leung, K. H. Tam et al., "Green, yellow, and orange defect emission from $\mathrm{ZnO}$ nanostructures: Influence of excitation wavelength," Applied Physics Letters, vol. 88, no. 10, Article ID 103107, 3 pages, 2006.

[33] R. Huang, S. Xu, W. Guo et al., "Nitrogen deep accepters in ZnO nanowires induced by ammonia plasma ," Applied Physics Letters, vol. 99, no. 14, Article ID 143112, 3 pages, 2011.

[34] L. Lyons, A. Janotti, and C. G. Van de Walle, "Why nitrogen cannot lead to p-type conductivity in ZnO," Applied Physics Letters, vol. 95, no. 25, Article ID 252105, 3 pages, 2009.

[35] L. Svob, C. Thiandoume, A. Lusson, M. Bouanani, Y. Marfaing, and O. Gorochov, "P-type doping with $\mathrm{n}$ and li acceptors of zns grown by metalorganic vapor phase epitaxy," Applied Physics Letters, vol. 76, no. 13, pp. 1695-1697, 2000. 

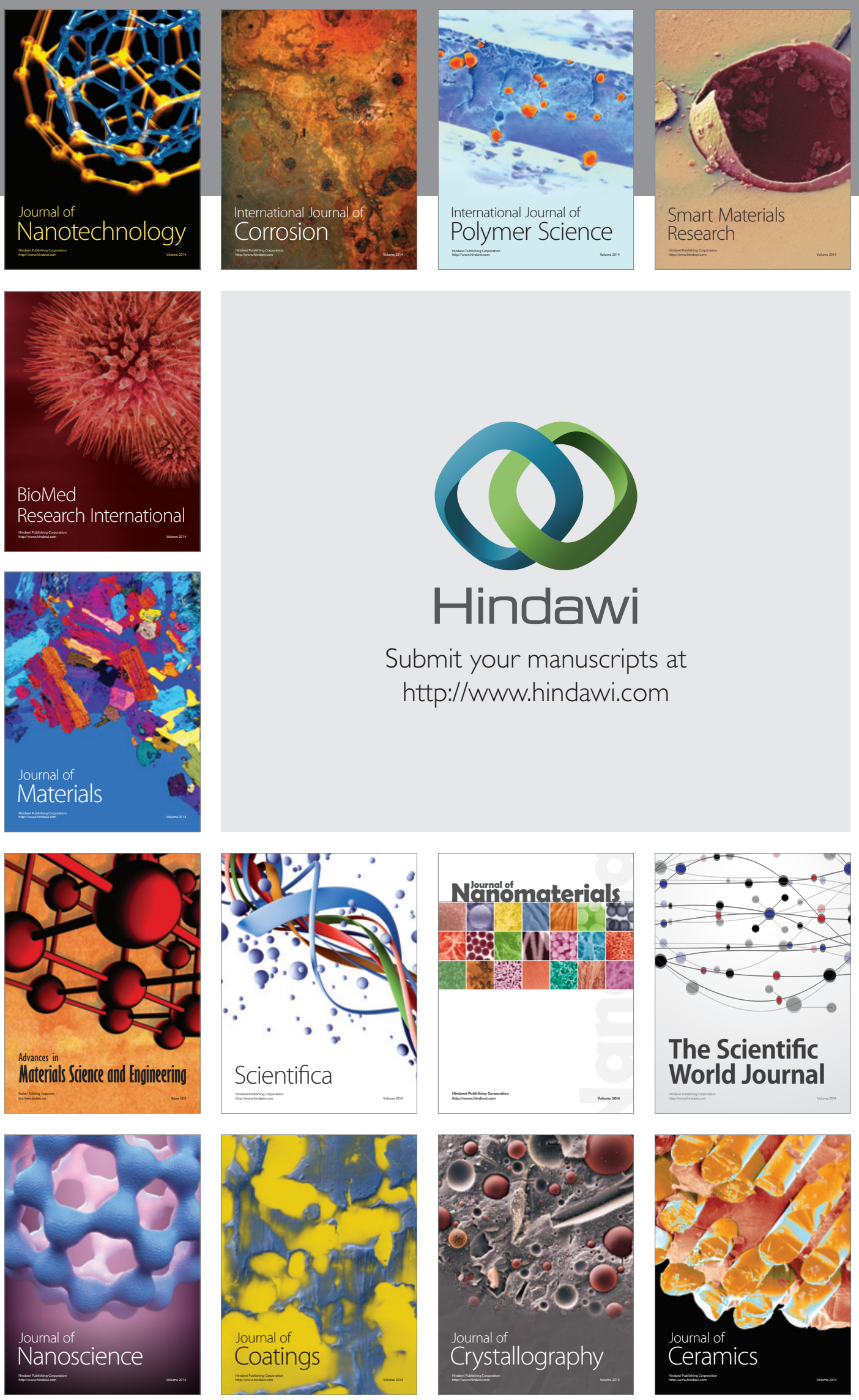

The Scientific World Journal

Submit your manuscripts at

http://www.hindawi.com

\section{World Journal}

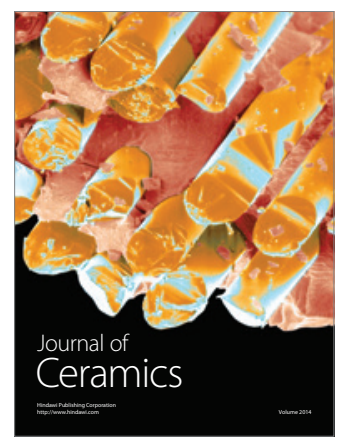

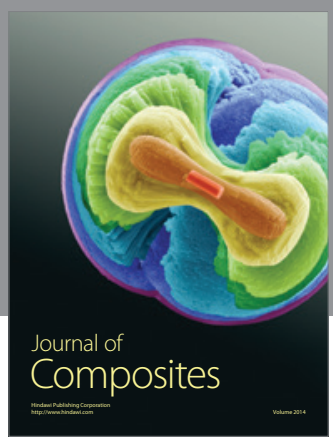
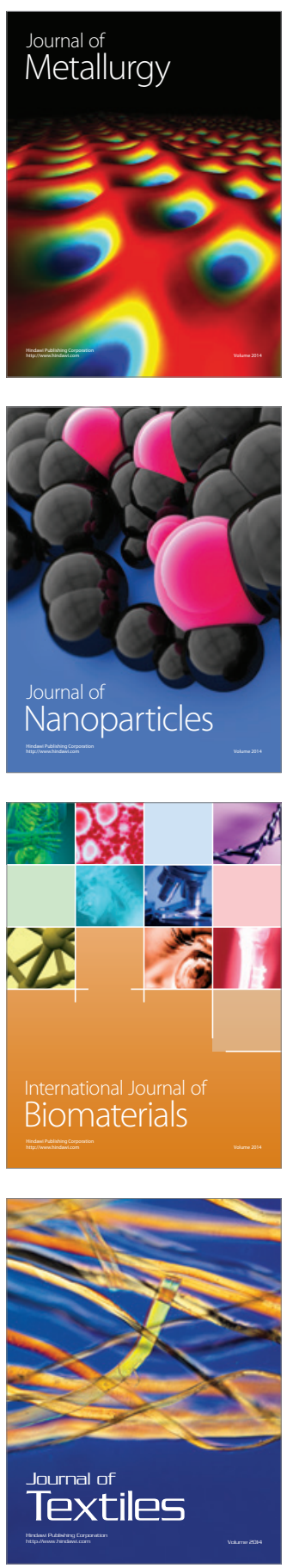